\title{
RELATOS DE CASOS
}

\section{MUCORMICOSE ÓRBITO-RINO-CEREBRAL ASSOCIADA À CETOACIDOSE DIABÉTICA. REGISTRO DE DOIS CASOS}

\author{
Jackson Maurício Lopes Costa1, Maria do Rosário da S.R. Costa2, Maria \\ de Lourdes Bonfim ${ }^{3}$ e Arnaldo Lopes Albarelli3
}

\begin{abstract}
Os autores registam dois casos de Mucormicose órbito-rino-cerebral ocorridos no Maranhão em 1980 e inicio de 1981, em pacientes portadores de cetoacidose diabética, enfatizando a gravidade desta moléstia causada por fungos oportunistas em pacientes que sofrem de distúrbios metabólicos graves.
\end{abstract} diabética.

Palavras chaves: Mucormicose orbito-rino-cerebral. Zigomicose. Cetoacidose

O termo zigomicose, recentemente proposto por Ajello e col ${ }^{1}$, em substituição à ficomicose (Joe e $\left.\mathrm{cols}^{6}\right)$, designa as infecçōes provocadas por fungos das familias Mucoraceae, Entomophthoraceae e Mortierrellaceae. Estes fungos são encontrados na natureza, isolados do ar, do solo e das fezes de vários animais como sapos, rãs e lagartixas, como contamitantes. Existindo determinadas condições predisponentes tornam-se patogênicos, provocando algumas vezes quadros graves, afetando principalmente o sistema nervoso central, trato respiratório e pele ${ }^{8}$.

Para Greer (1966), o termo mucormicose deve ser reservado somente às infecções causadas por fungos da familia Mucoraceae 5 . Os mesmos podem determinar infecçōes agressivas e fulminantes em certas condiçōes clínicas como cetoacidose diabética para a mucormicose órbito-rino-cerebral e leucemia ou linfoma para a forma pulmonar ou disseminada; no primeiro caso a tendência è a invasão vascular, penetração de diferentes camadas, atingindo a luz dos vasos, onde crescem abundantemente terminando por lesar o endotélio dando origem a formação de trombos, enfartos e produção de necrose com disseminação do processo infeccioso. A localização inicial do fungo e cavidade nasal ou palato, estendendo-se para os seios paranasais adjacentes, progredindo através do etmóide difundindo-se para a região retroorbitária e cérebro 4910 .

O quadro clinico comumente observado é de uma meningoencefalite, com sinais também de infecção retroorbitária, geralmente unilateral, traduzida

1. Clinica Médica do Hospital Presidente Dutra INAMPSMA. Endereço Atual: Núcleo de Medicina Tropical e Nutrição, Universidade de Brasília, 70910 Brasilia-DF.

2. Clínica Médica do Hospital Presidente Dutra INAMPSMA. Endereço atual: Hospital das Forças Armadas, Brasilia-DF.

3. Faculdade de Medicina da Universidade Federal do Maranhão.

Recebido para publicação em 29/4/1985 por celulites retroorbitárias. No presente trabalho, descrevemos dois casos em que os pacientes apresentavam cetoacidose diabetica, cujo estudo inclui o acompanhamento clínico, as dificuldades terapêuticas encontradas e os aspectos histopatológicos das lesões.

\section{APRESENTAÇÃO DOS CASOS}

Caso 1 - Paciente do sexo feminino, 57 anos, mulata, doméstica, procedente de São Luís-MA. Diabética há 10 anos, nos últimos dias que antecederam a internação, apresentou astenia generalizada, dispnéia, agitação psicomotora, dislalia, emagrecimento e diurese aumentada. Quando da internação $(23 / 05 / 80)$ apresentava-se em mau estado geral, coma superficial, com freqüência cardiaca $120 \mathrm{bat} / \mathrm{min}$., pressão arterial $220 \times 90 \mathrm{mmHg}$, afebril, desidratada e descorada. Internando com diagnóstico de coma diabético. Com tratamento insulínico melhorou da cetose e da desidratação. Posteriormente, apresentou edema inflamatório infra e supra-orbitário, na hemiface esquerda, com conseqüente protusão orbitária. A boca apresentava destruição óssea, com perfuração do palato, lesões vegetantes friáveis e extensa placa necrótica, avulsão dentária espontânea, apresentando ainda quadro pneumônico. Esteve internada por 20 dias quando faleceu. Foi medicada com Ampicilina $\mathrm{lg}$ de $4 \mathrm{em} 4 \mathrm{~h}$, Oxacilina $2 \mathrm{~g}$ de $6 \mathrm{em} 6 \mathrm{~h}$ por via endovenosa e hidratação venosa.

Os hemogramas revelaram leucocitose com desvio para a esquerda, a glicemia esteve sempre elevada, com nivel máximo de $380 \mathrm{mg} / 100 \mathrm{ml}$. Sedimento urinário encontrava-se normal, pesquisa de fungos na secreção do palato negativa, feito biópsia da lesão com histopatologia.

Caso 2 - Paciente de sexo masculino, 49 anos, branco, comerciante procedente de São Luis-MA. Diabético há 12 anos, apresentou dor em pontada no maxilar superior direito, febre, sonolência e desorientação, emagrecimento e diurese aumentada. Internou-se em 13/01/81 com agravamento do qua- 
Relato de Caso. Costa JML, Costa MRSR, Bonfim ML, Albarelli AL. Mucormicose órbito-rino-cerebral associada à cetoacidose diabética. Registro de dois casos. Revista da Sociedade Brasileira de Medicina Tropical 18: 263-265, Out-Dez, 1985

dro. Antecedentes de tuberculose pulmonar e etilismo crônico. $\mathrm{Na}$ internação apresentava-se em mau estado geral, coma superficial, com freqüência cardíaca 86 bat/min.. pressão arterial $110 \times 70 \mathrm{mmHg}$, febril, desidratado e descorada. Internou-se com diagnostico de coma diabético. Ao exame da face observamos protusão orbitária, ptose palperal à direita, com edema de característica inflamatória, lesão ulcerada na asa do nariz lado direito com necrose negra central. Posteriormente, evoluiu com sinais de irritação meningéia, ausência de reflexos profundos e coma profundo. Esteve internado por 5 dias, quando veio a falecer. Foi medicado com antibioticoterapia e Anfotericina B.

$\mathrm{O}$ hemograma revelou leucocitose com desvio para a esquerda, glicemia elevada, nivel máximo de $420 \mathrm{mg} / 100 \mathrm{ml}$. Sedimento urinário com piocitos, hemácias 18 a 20/campo, cristais de ácido úrico, esporos de monilias. Os niveis de uréia e creatinina mostravam-se elevados, realizada biópsia da lesão.

Exames histopatológicos dos materiais biopsiados da orofaringe: Fragmentos irregulares de tecido medindo em conjunto $0,10 \mathrm{~cm}$ de diâmetro, de cor acastanhada. Ao exame histopatológico revela fragmento de tecido epitelial pluriestratificado e conjuntivo com reação inflamatória, infiltrado celular constituido por polimorfonucleares, linfócitos, plasmócitos, tecido necrótico e formação eosinofílica. apresentando micélios filamentosos, contínuo ou cenocítico, com órgão de frutificação assexuada (esporângios) (Fig. 1,2). Nos tecidos examinados observou-se hifas longas não septadas com ramificaçōes laterais dispostas em ângulo quase reto (Fig. 3,4 ).

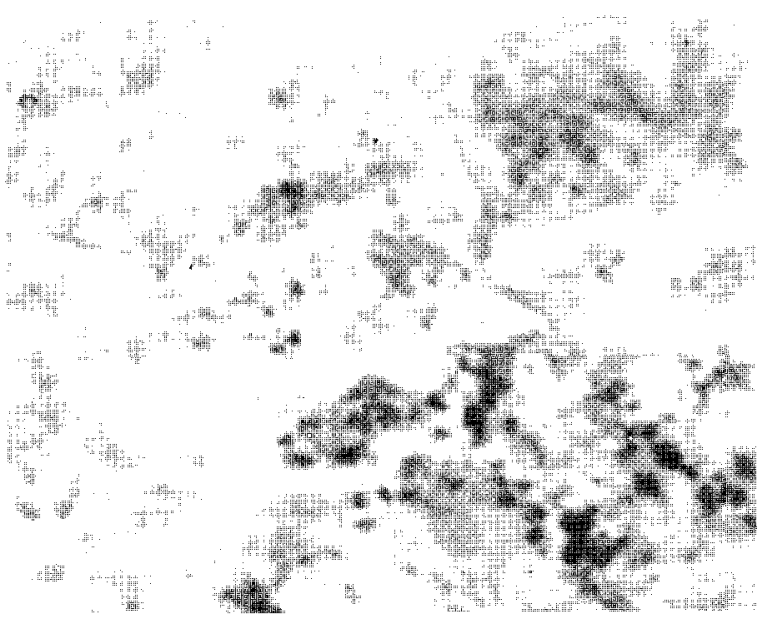

Fig. 1 - Micélios filamentosos, contínuos ou cenociticos.

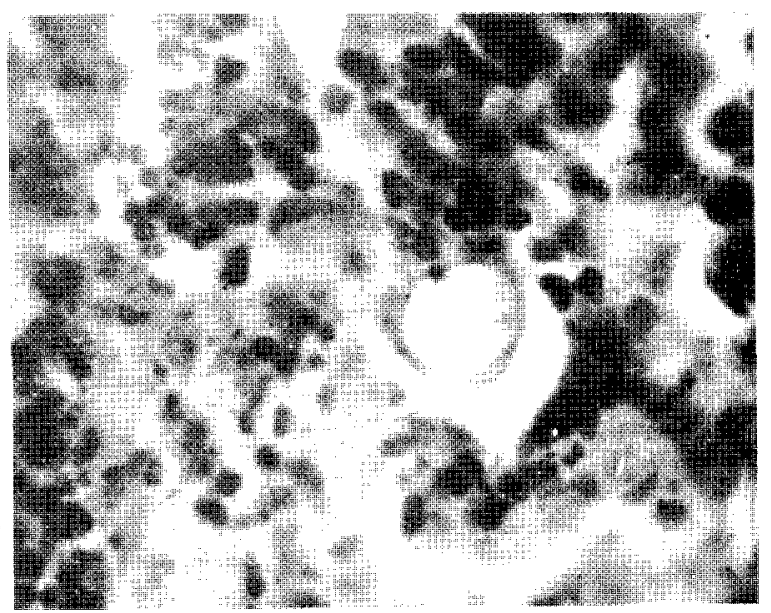

Fig. 2 - Órgãos de frutificaçāo assexuada (esporângios).
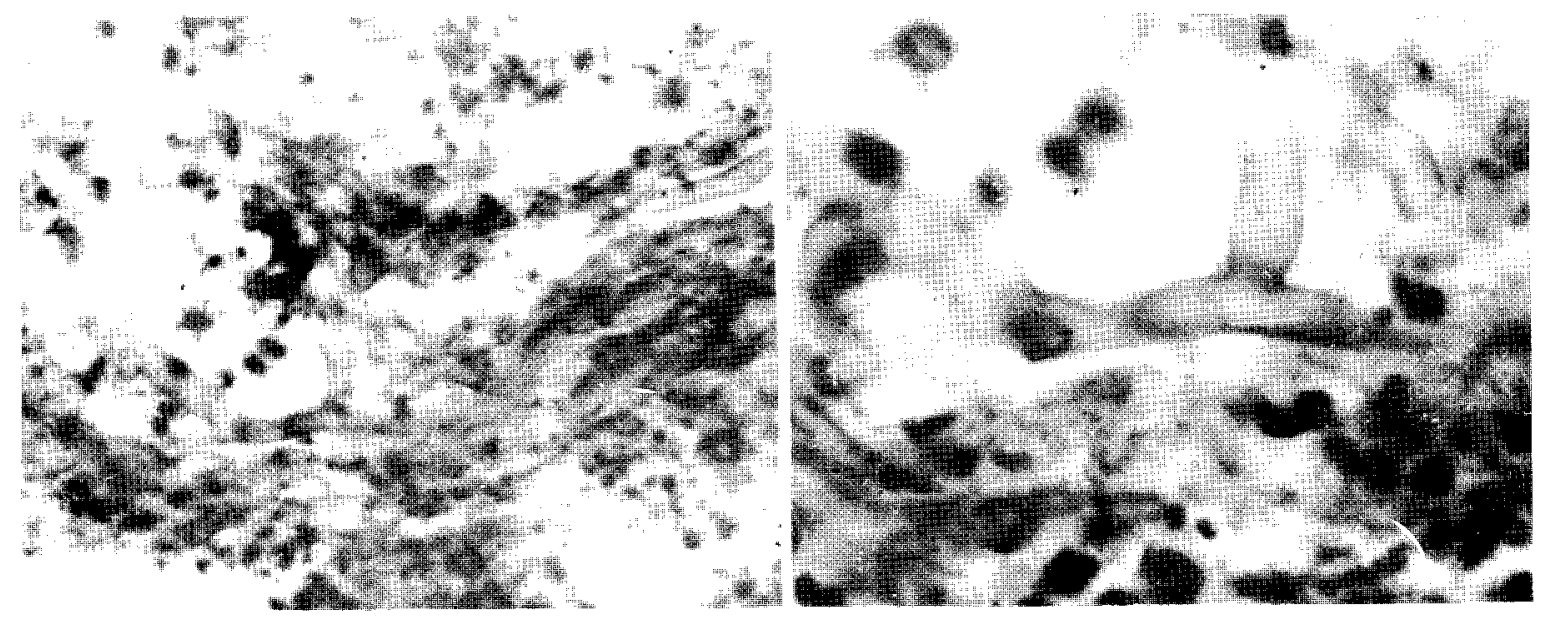

Fig. 3 e 4 - Nos tecidos sāo vistos um grande número hifas longas, não septadas, com ramificacões laterais dispostas quase em ângulo reto. 
Relato de Caso. Costa JML, Costa MRSR, Bonfim ML, Albarelli AL. Mucormicose órbito-rino-cerebral associada à cetoacidose diabética. Registro de dois casos. Revista da Sociedade Brasileira de Medicina Tropical 18: 263-265, Out-Dez, 1985

\section{DISCUSSÃO}

Os pacientes descritos receberam o diagnóstico baseando-se nos aspectos clínicos, evolução dos mesmos e dados histopatológicos, observando-se os aspectos morfológicos aliados às lesões determinadas por estes cogumelos. As lesōes macroscópicas são do tipo ulcerativo, as microscópicas mostram necrose, lesões vasculares com presença de micélios dicotômicos e não septados. Portanto detemo-nos à morfologia do cogumelo, por não termos procedido ao isolamento e posterior reprodução experimental da doença. No Maranhão são os primeiros casos observados em um periodo de 10 anos (1971 a 1981) conforme levantamento de prontuários feito em cinco hospitais de São Luis-MA. Dentre as zigomicoses podemos dizer que a Rinoentomophtoromicose foi relatada em nosso estado. Recentemente foram publicados dois casos, nos quais o comprometimento facial foi predominante 211 .

Destacamos alguns pontos importantes na evolução dos casos de mucormicose orbito-rino-cerebral: 1) a faixa etária acometida geralmente entre a 4 a e 5 a década da vida; 2 ) evolução rápida agressiva e letal da doença, ou determinando graves seqüelas aos sobreviventes; 3 ) diagnóstico dificilmente dado em vida, exigindo técnica aprimorada para a colheita do material para exame histopatológico, tendo em vista a maioria dos diagnósticos serem pós-morte; 4 ) a terapêutica à base de Anfotericina $B$ nào mostrou-se efi$\mathrm{caz}$, isto associado ao grave estado dos pacientes, $\mathrm{O}$ que também foi avaliado por outros autores ${ }^{3} 7$.

Do exposto justifica-se a apresentação do presente trabalho tentando alertar sobre a crescente freqüencia com que ocorrem infecçōes por agentes oportunistas. sobretudo em pacientes com graves distúrbios metabólicos.

\section{SUMMARY}

The authors report two cases of Orbitorhinocerebral phycomycosis observed during 1980 and the beginning of 1981 in Maranhão, Brazil. Both patients had poorly controlled diabetes mellitus, which emphasises the importance of a decrease in host defenses in opportunistic infections caused by this fungus.

Key words: Orbito-rhinocerebral. Mucormycosis. Zygomycosis. Diabetic ketoacidosis.

\section{REFERÊNCIAS BIBLIOGRÁFICAS}

1. Ajello L. Dean DF, Irwir RS. The zygomycete saksenae vasiformis as pathogen of human with a critical review of the etiology of zygomycosis. Mycologia 68: 52-62, 1976.

2. Bittencourt AL, Queiroz AC, Cruz Filho JC, Barreto E, Costa JML, Couto JAA, Costa MRR. Rinoentomoftoromicose. Medicina Cutânea 11: 177-182, 1983.

3. Blitzer A, Lawson W, Meyers BR, Biller HF. Patient survival factors in paranasal sinus mucormycosis. The Laryngoscope 90: 635-648, 1980.

4. Franco MF, Iriya K. Ficomise órbito-rino-cerebral associada à cetoacidose diabética. Registro de um caso. Revista do Instituto de Medicina Tropical de São Paulo 12: 354-363, 1970 .

5. Greer DL, Friedman L. Studies in the genus Basidiobolus with reclassification of the species pathogenic for man. Sabouraudia 4: 231-241, 1966.

6. Joe LK, Eng NT, Tsokronegere S, Emmaus CW. Phycomycosis in Indonesia description of a case affecting the subcutaneous tissue. American Journal of Tropical Medicine and Hygiene 9: 143-148, 1960.

7. Larribaud J, Marey J, Siscamps G, Pazat R. Un cas de Rhinophycomycose. Presse Medicale 77:1011-1012, 1969.

8. Lacaz CS, Porto E, Martins JEC. Micologia Médica. Sarvier, 7a edição, 1984.

9. Mcbride RA, Corson JM, Damin GJ. Mucormycosis: Two cases of dissemineated disease with cultural identification of Rhyzopus. Review of literature. American Journal of Medicine 28: 832-846, 1960.

10. Pillsburry HC. Fisher ND. Rhinocerebral mucormycosis. Archives of Otolaryngology 103: 600-604, 1977.

11. Silva JF, Silva WM. Dantas JC, Assunçào ACR, Teive Oliveira MM S. Rinoentomoftorose. Registro de um caso. Revista de Patologia Tropical 4: 101-106, 1975. 